\title{
Movilización social y petróleo en el sur de Veracruz*
}

\section{Angela Ixkic Bastian Duarte}

Por más de medio siglo, la extracción intensiva de petróleo ha transformado radicalmente la forma de vida de las comunidades agrícolas y pesqueras del Golfo de México, ocasionando graves daños a la salud y los ecosistemas. La población local paga los costos del deterioro ambiental que las políticas económicas explican como «externalidades». El descontento ha llevado a la movilización social. El presente texto narra la experiencia de la Asociación de Productores Ecologistas Tatexto A.C., organización de campesinos y pesadores afectados por la contaminación petrolera en el sur de Veracruz.

INTRODUCCIÓN

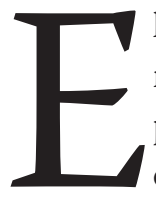
l petróleo es un elemento central en la historia reciente de México. A partir de la expropiación de la industria petrolera, en 1938, este recurso fue entendido como el factor que posibilitaría el desarrollo, la independencia, la modernidad y la soberanía. Pocos datos bastan para mostrar la relevancia política y económica de este bien natural para nuestro país: México es el cuarto productor a nivel mundial, el onceavo en reservas de crudo y la paraes- tatal encargada de la extracción y del procesamiento, Petróleos Mexicanos (Pemex), es la tercera compañía en importancia a nivel mundial. ${ }^{1}$

Sin embargo, los beneficios que los hidrocarburos han traído al país vienen acompañados de graves y complejos problemas hasta ahora sin solución. Poco más de medio siglo la extracción intensiva ha transformado radicalmente la forma de vida de las comunidades agrícolas y pesqueras del Golfo de México, la región petrolera más importante del país, ocasionando graves daños a la salud de los habitantes y a los ecosis- 


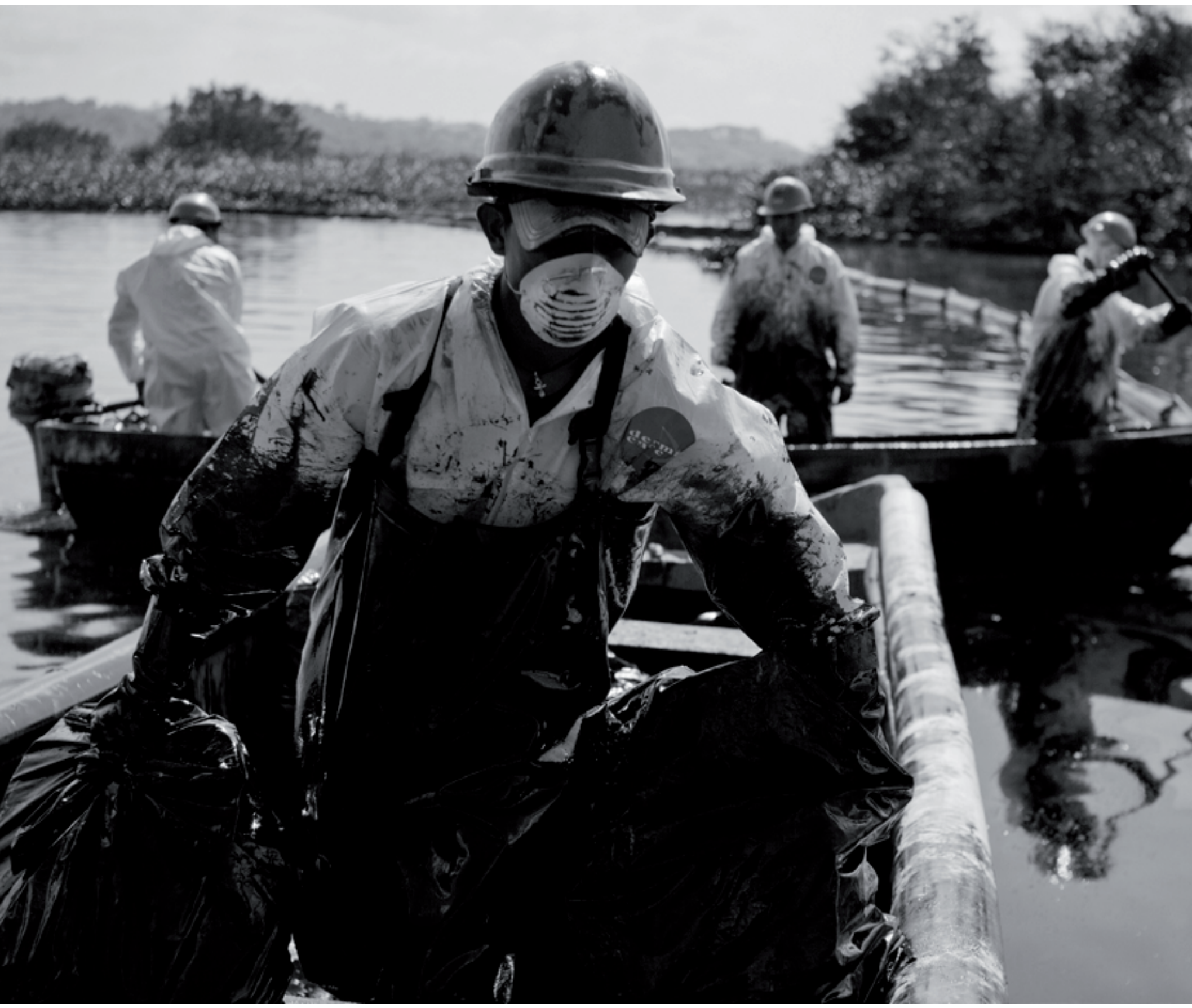


temas. Greenpeace explica que en la región del Golfo de México ha ocurrido un ecocidio de proporciones dramáticas con un alto impacto en términos de salud pública y degradación de las fuentes de agua y de los suelos. ${ }^{2}$ Frecuentemente ocurren derrames y accidentes durante las tareas de limpieza, carga y descarga de buques. Se han vertido sistemáticamente, durante décadas, desechos tóxicos sin tratamiento alguno en innumerables puntos de la región.

Por tanto, los ríos están fuertemente contaminallo y Páez demostraron la existencia de muy elevados valores de hidrocarburos aromáticos policíclicos (HAP) en puntos del río Coatzacoalcos donde las descargas eran constantes o donde existía una intensa actividad petrolera. ${ }^{3}$ Los HAP son toxinas peligrosas con un efecto cancerígeno documentado. Se ha vinculado al cáncer de estómago y de piel, así como a malformaciones en los fetos y recién nacidos. 20 años después, Bozada y Bejarano hablan de la presencia de HAP y de otros elementos altamente cancerígenos como benzo (a) pireno y benzo (ghi) perileno en 19 especies de peces, moluscos y crustáceos del río. ${ }^{4}$ El Instituto de Ecología en un estudio realizado en el 2007, también en Coatzacoalcos, constata la presencia de compuestos orgánicos y metales pesados en suelo y sedimento, y asegura que la contaminación por compuestos orgánicos persistentes (COP) y por algunos metales como plomo $(\mathrm{Pb})$ se encontraba en determinadas plantas y animales, en algunas de las cuales se detectaron daños al ADN.

Los periódicos locales hablan de la salinización de las tierras de cultivo, de la contaminación del aire y de los cuerpos de agua; del incremento de casos de cáncer y de las afectaciones al corazón, sistema nervioso central y sistema respiratorio; además de problemas en la piel, leucemia y niños que nacen con malformaciones. ${ }^{5}$ A lo anterior, hay que sumar el daño ocasionado por el acondicionamiento de las áreas donde se ubican las industrias.

Hay que considerar, también, la contaminación que implica la operación misma de las plantas petroquímicas y el constante riesgo que representa la extendida red subterránea de ductos y poliductos que atraviesa la región, así como el ya conocido impacto ambiental de la construcción de carreteras y demás sistemas de conexión terrestre. En este contexto, se desarrolla la vida de los campesinos, pescadores y pequeños ganaderos, indígenas y mestizos, ejidatarios, pequeños

propietarios, avecindados y comuneros que habitan las zonas petroleras.

En el sur de Veracruz, así como en otras regiones petroleras del país que han subordinado sus actividades productivas y los recursos naturales al desarrollo de la industria petrolera, se observa una clara contradicción entre la riqueza ofrecida por la naturaleza y los niveles de pobreza de los habitantes. La población local paga los costos del deterioro ambiental que las políticas económicas explican como «externalidades». El descontento que este hecho produce, sumado a los efectos que la degradación ambiental ha tenido en la salud y las formas de vida de campesinos y pescadores, ha llevado a que estos se movilicen e impulsen procesos organizativos, como el de la Asociación de Productores Ecologistas Tatexco A.C. (APETAC).

\section{EN EL SUR DE VERACRUZ}

A mediados de la década de los años noventa, pescadores y campesinos de Ixhuatlán de Sureste y de la cuenca media del río Coatzacoalcos repararon en la creciente mortandad del ganado y de los peces, en la disminución en la producción agrícola, en la evidente degradación de la calidad del agua y en el incremento de enfermedades. Los pobladores atribuyeron estos hechos a que la planta Agata de Pemex Exploración y Producción vertía sus desechos al Arroyo Grande, colindante con sus tierras. Se dieron a la tarea de observar sistemáticamente e iniciar un registro de estos hechos.

Pemex comenzó a verter los desechos de esa planta en piscinas clandestinas ubicadas en los ejidos. Estas piscinas o represas son excavaciones de aproximadamente 80 x 80 metros y entre seis y ocho metros de profundidad. Los pobladores localizaron 60 de ellas, observaron la rutina de las pipas y lograron reconstruir sus horarios y trayectos. El 10 de agosto de 1998 reunieron a una comitiva integrada por un representante de la Secretaría de Medio Ambiente y Recursos Naturales-Coatzacoalcos (Semarnap), uno de la Dirección General de Asuntos Ecológicos del Estado, un miembro de Greenpeace y uno del Centro Mexicano de Derecho Ambiental (Cemda) y los llevaron a una piscina ubicada en el ejido Felipe Berriozábal donde sería depositada, según los registros realizados, una descarga de desechos. Los integrantes de la comitiva sorprendieron a un camión de plataforma vertiendo lodos tóxicos 
y lo detuvieron; tomaron muestras de la sustancia y las enviaron al Instituto de Ciencias del Mar y Limnología de la Universidad Nacional Autónoma de México para su análisis. Los resultados revelaron una elevada concentración de hidrocarburos. ${ }^{6}$

El 26 de octubre de 1998, con la asesoría del Cemda y Greenpeace, los ejidatarios presentaron una denuncia penal ante un juez federal por el derrame premeditado de desechos tóxicos a cielo abierto en tierras ejidales. En 2001, tres funcionarios de Pemex fueron encontrados culpables de delitos ambientales. Ésta fue la primera denuncia, ante un juez federal, desde la inclusión de los derechos ambientales a la Ley General del Equilibrio Ecológico y la Protección al Ambiente que involucraba la presencia de desechos peligrosos. Según documenta Greenpeace y explican integrantes de APETAC, fue también la primera vez que se ejerció una acción penal y que se dictaron órdenes de aprensión contra funcionarios de la paraestatal por delitos ambientales. ${ }^{7}$

Después de este triunfo legal, cada vez más pescadores y campesinos comenzaron a registrar distintos eventos en sus comunidades, como la presencia de otros depósitos de desechos o escurrimientos. Se crearon comités en cada ejido para vigilar y registrar, de forma sistemática, lo que ocurría. De este proceso nació APETAC. La organización reúne a pescadores y agricultores, campesinos de todos los ejidos de Ixhuatlán del Sureste y de buena parte de la cuenca media del río Coatzacoalcos; muchos de ellos son migrantes económicos, indígenas provenientes de Chiapas y Tabasco.

El trabajo de esta asociación ha logrado vincular lo político, lo social y lo ambiental; está dirigido a la denuncia y la difusión de la problemática provocada por los derrames, las filtraciones y el manejo de desechos tóxicos. Poco a poco ha ido incorporando otros temas y estrategias como la medición y la denuncia de la contaminación del aire, provocada también por la industria petroquímica o la promoción de proyectos de corte ecológico. Entre 2006 y 2011, APETAC impartió talleres en varios municipios acerca de temas como cambio climático, contaminación ambiental e impacto de las industrias en la zona. En estas actividades colaboró, a veces, la ONG Fronteras Comunes, otras veces el párroco Zaragoza, municipio vecino, y las Comunidades Eclesiales de Base de Ixhuatlán del Sureste. De igual forma, la organización ha realizado actividades para promover la lombricomposta, el manejo ecológico de plagas, así como algunos proyectos productivos que incidan en la economía de la población local. En julio de 2011 organizó un foro con la participación de especialistas para discutir la problemática ambiental de la región.

APETAC ha establecido vínculos con organizaciones sociales y no gubernamentales, con investigadores de distintas instituciones académicas nacionales e internacionales y con funcionarios ubicados en puestos estratégicos. Estas relaciones les ha permitido contar con aval científico, asesoría jurídica y cierta difusión, así como ir construyendo redes de solidaridad. Un ejemplo es la capacitación para tomar muestras de aire con un método casero, el cubeteo, ofrecido por la ONG internacional Global Community Monitor. ${ }^{8}$ El cubeteo es una técnica que consiste en tomar muestras de aire en cubos de 20 litros mediante dispositivos y filtros, con el fin de enviarlos luego a un laboratorio para su análisis. Este método permite que los integrantes de la comunidad participen más activamente en la vigilancia ambiental y al mismo tiempo permite que puedan tomarse muestras de aire sin la presencia de un técnico especializado. Las muestras son enviadas, respetando exigentes protocolos, a un laboratorio certificado para su análisis. Con estas pruebas APETAC demostró, en 2006, la existencia de 23 químicos tóxicos en el aire de Minatitlán, tres de los cuales exceden los niveles permitidos en Estados Unidos. ${ }^{9}$

La organización realiza estas pruebas cada cierto tiempo. Le llama cubeteo porque una parte del equipo necesario para tomar las muestras tiene la forma de una cubeta. El proceso consiste en detectar zonas donde la población presenta con frecuencia determinados síntomas, como dolores de cabeza y vómito. La brigada de cubeteros toma una muestra con una bolsa que succiona el aire y la envía a los laboratorios donde será analizada. En 2010 y 2011, la organización tomó 20 muestras y las envió para su análisis a los laboratorios Columbia Analytical Service - certificados por la Agencia Norteamerica de Protección Ambiental (EPA) -,${ }^{10}$ ubicados en California, Estados Unidos. Estos análisis han sido financiados por la Universidad de York de Toronto, Canadá, con apoyo de la geógrafa Ann Zalik, investigadora de esta universidad, quien ha trabajado con la organización durante más de una década.

\section{REFLEXIONES FINALES}

La lucha de estos campesinos y pescadores no puede entenderse analizando únicamente los aspectos relati- 


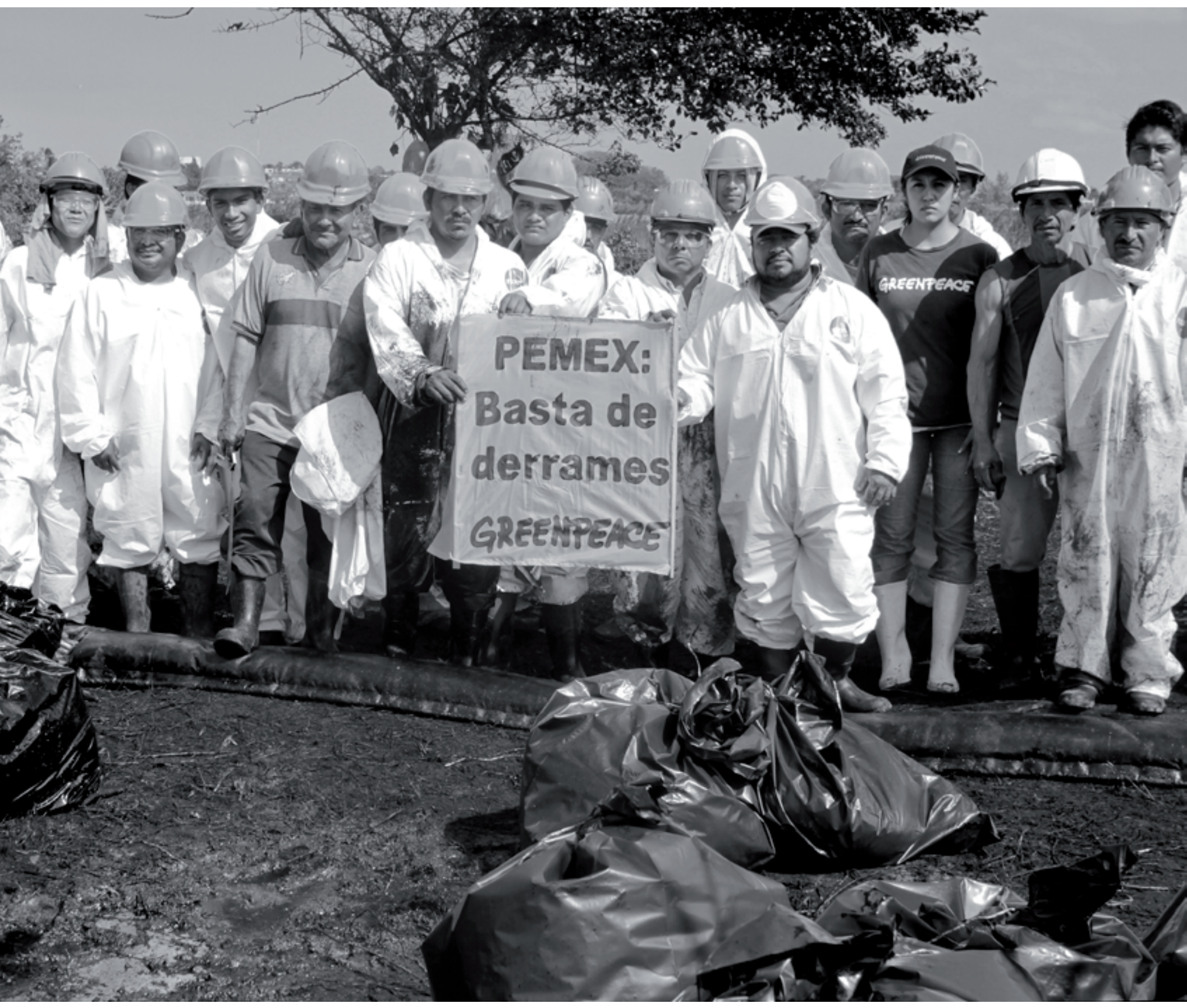


vos al ambiente: los daños a la ecología ocurren en un contexto marcado por relaciones de poder en el que se entrelazan las trayectorias de los distintos actores. Sus argumentos involucran lo ambiental como respuesta a los evidentes daños provocados por Pemex, por sus filiales y por las otras industrias de la zona, pero estas afectaciones no son ataques a la naturaleza, de forma aislada, sino a los espacios en los que transcurre la vida de los pescadores y los campesinos: tierra, agua, plantas y animales que permiten la subsistencia.

No sorprende que las reivindicaciones ambientales de los reclamantes de Veracruz no sean conser- vacionistas. No proponen conservar la naturaleza por sí misma, sino transformar las formas de relacionarse con ella para que las comunidades no sean dañadas durante la extracción y transformación de recursos, sino beneficiadas por estos procesos. La experiencia organizativa descrita apunta a un proyecto de desarrollo que considere a sus comunidades, que las coloque en el centro. Sus estrategias, sus alianzas y su discurso aluden a demandas más amplias que incluyen la necesidad de una democracia real, de mayor participación ciudadana y de una evaluación de costos y beneficios del actual modelo de desarrollo.

\section{Referencias}

* Una discusión más elaborada se presentará en el libro Conflictos, conflictividades y movilizaciones socioambientales en México: problemas comunes, lecturas diversas, coordinado por María Fernanda Paz y Nicholas Risdell, que será publicado por la Universidad Nacional Autónoma de México.

1 〈http://www.industriapetroleramexicana.com/2012/03/datos-que-debes-saber-acerca-del-petroleo-y-la-industria-petrolera/s.

2 Greanpeace México (2009), «Ixhuatlán: combatir la impunidad ambiental», Este país, 17 de abril.

3 Susana Villanueva, Alfonso Vázquez Botello y Federico Páez Osuna (1986), «Presencia de algunos metales pesados en organismos del río Coatzacoalcos y laguna del ostión, Veracruz», Memorias del Iv Curso y Simposio Internacional so- bre Biología de la Contaminación, México, Universidad Nacional Autónoma de México.

4 Lorenzo Bozada Robles y Fernando Bejarano González (2006), Los contaminantes orgánicos persistentes en el istmo mexicano, Texcoco, RAPAM.

5 Rubén Rojas (2006), «Pemex es nuestra muerte», Diario de Xalapa, 13 de febrero.

6 Greenpeace México (2009), op. cit.

7 〈http://estepais.com/inicio/historicos/107/12_medio\%20 ambiente_ixhuatlan_greenpeace.pdf $>$.

8 〈http://gcmonitor.org/index.php〉.

9 〈http://zapateando2.wordpress.com/2006/11/23/la-contaminacion-en-veracruz-un-foro/>.

$10 〈$ http://www.epa.gov/〉. 